\title{
Sandplay Therapy Case Study: A Boy with Difficulty in Emotional Regulation
}

\author{
Eun Kyung Jang*
}

\begin{abstract}
<Abstract>
For this study the researcher conducted sandplay therapy with a client who exhibited passiveaggressive behavior due to his difficulty in emotional regulation. After a total of 34 sessions, the client was better able to regulate and express emotions and his mother developed efficacy in her parenting. $\mathrm{H}$ is mother had experienced severe anger and depression when she was pregnant with the client. The mother's depression lasted after childbirth. She did not seem emotionally interactive with the client and only provided basic care for him. The theme of the client's sandplay mainly dealt with his mother's anger. Sandplay therapy initially proceeded very slowly, in a passive client's pattern. As the sandplay therapy progressed, the client's self and ego became stronger at dealing with anger issues related to his mother. $\mathrm{H}$ is emotional problems were able to be adjusted.
\end{abstract}

Keywords : sandplay therapy, emotional regulation, passive aggression, ego development

* Department of Consumer and Family Sciences Sungkyunkwan University (unending@ naver.com) 
Journal of Symbols \& Sandplay Therapy, Vol.6 No.2.

\section{Introduction}

It is highly important to recognize and regulate our emotions, especially as they influence our interpersonal relationships. Our initial expression of emotions is to communicate for our survival, and later to develop attachment with our caregiver. Emotions develop through relationships. Continued emotional response by the caregiver enables the infant to express positive emotions as well as to interact and regulate emotions. But an individual who was not able to learn how to recognize and regulate his or her emotions have difficulty recognizing the emotions of others. That is when problems occur in relationships.

The first stage of emotional development is differentiation. Emotions can largely be divided into two: primary emotion and secondary emotion. Primary emotion is also called basic emotion, examples of which include happiness, anger, surprise, fear, disgust, sadness, joy and so on. Primary emotions take place early in infancy. But emotions such as embarrassment, envy, guilt and pride take place after the age of one. These are secondary emotions, otherwise known as complex emotions. At this stage, it is important that the emotions and the infant's recognition of them coincide. The caregiver should sensitively respond to and accept the infant's expression of emotions. Differentiation of emotions normally occurs before the age of 3.5. When differentiation does not take place normally, possibility of the infant's experiencing a personality disorder or psychosis becomes high. The second stage is recognition. Maladaptive interaction brings problems to the ability to recognize emotions. For example, a child who is a victim of physical abuse has a tendency to recognize anger even when violence is not present and is predicted to display aggressive behaviors. Emotion recognition is important in our relationships with others. Only when we recognize our emotions will we be able to respond to that of others. This stage occurs from the age of 3.5 , and continues until the formal operational stage. When trouble occurs in this stage, there is an increased risk of interpersonal problems and neurosis. The last stage is regulation. Emotional regulation is a combination of recognition, behavior and social process. Regulation is essential for normal development; a major cause of mental disorder is the failure of emotional regulation. Internalized problem behaviors rise from failure to regulate emotions such as sadness, and externalized problem behaviors are caused by 
the failure to regulate emotions such as anger (Cicchetti \& Cohen, 2006).

As stated above, development of emotions occurs in early infancy. Infancy is when the development of the right hemisphere takes place. Trevarthen said that the right hemisphere develops more than the left hemisphere from the 25th week of pregnancy, and such phenomenon takes place until 2 years after birth, which is when the left hemisphere begins to develop actively (1996, as cited in Schore, 2014). Main functions of the right hemisphere are the ability to understand the reality as a whole, regulation of emotional behaviors in relation to the mother, and integration of emotions, attitude and autonomic nerves. These functions take place before anything else as they are the basic functions for survival (Schore, 2014). Therefore, doing works related to the right hemisphere is crucial in resolving problems related to emotional regulation.

Schore pointed out that the effect of psychotherapy is related to the ability become the regulator of the client's unregulated emotions (2014). Such effect can take place when the implicit right brain raises the level of trust and safety at an unconscious level.

In this vein, sandplay therapy can be effective in treating clients. Sandplay therapy is a play involving both the senses and motor activity, which is the method of play as well as communication in early infancy. Primary experiences in infancy are emotional, sensory-motor, preverbal and presymbolic. They are recorded in implicit memory that forms the basis of the unconscious. Implicit memory stores information on the mother's response to the child, information expressed through the mother's body as well as information obtained through mother-child interaction. It is manifested in play as creative representations. Sandplay therapy enables clients to have relational interaction with the creative expressions of emotions and feelings, and also activates primary senses and emotional energies in the deep unconscious. In sandplay, the client chooses figures and place or displace them in or from the sandtray. The use of figures allows the client to represent in various ways the fragments in the psyche, things that they rejected or did not recognize as their own. It also makes the creation of a new Self image possible (W einberg, 2014).

In this way, sandplay therapy provides the client the opportunity to express themselves freely and voluntarily under a relationship of trust with the therapist. By using symbols in the 
sandtray-a space strictly for the client only-they are able to express the world of their images and experience the world of their unconscious. This experience facilities the union of the conscious and the unconscious, which were disconnected, so as to enable healing. The client's voluntary process of self-realization allows their innate healing power to be exercised at a maximum, which enables them to resolve their problems. Through the union of the conscious and the unconscious, they are able to connect to their true Self and achieve individuation. Young children in particular express their tensions and the unconscious through representations of their fantasy through play, making it possible to organize themselves (Kim, 2010).

According to Jung, fantasy is a means and experience to get to know the unconscious. He explained that fantasizing is the best mental activity that unites the conscious and the unconscious. By externalizing the unconscious we are able to observe our mental state and come face to face with it, which leads to the union of the conscious and the unconscious (Lee, 2006).

This paper covers the case of a client who was not able to develop the ability to recognize and regulate his emotions through a relationship with a depressed mother. He thus experienced difficulties in not only the mother-child relationship but also peer relationship. The paper describes his sandplay process though which he was able to recognize his emotion-related issues, regulate his emotions through the development of the ego and the Self, and also develop his masculine.

\section{Case Overview}

\section{The client and his problems}

The client was a 6-year-old boy. He was rather small and skinny, with fair skin. $\mathrm{H}$ is mother brought him to therapy because he too often turned sulky for the most trivial matters, and showed his resistance to different situations by curling up his body and do nothing in silence. 


\section{The client's history}

It was during her pregnancy when the mother quit work, from which she received an extreme amount of stress. The reason for her leaving the job was interpersonal relationship issue, which caused her to suffer from extreme depression and anger. Her severe morning sickness did not help either. In fact, the mother was not so happy about her pregnancy.

After being born, the client cried nonstop to be fed at the neonatal unit. And when the nurse did feed him, he would eat until throwing up and then would try to continue eating. Concerned, the nurses asked the mother whether she had experienced extreme difficulties during pregnancy. The mother began working again when the client became four months old and he was taken care of at his babysitter's home, where he would spend 4-5 hours a day. The mother said that she regrets not giving him toys or anything that could be symbolic of her when having the babysitter take care of him. She also admitted that she seemed to have neglected the client even when they are together because she was too tired and had no energy to talk. Moreover she was soon pregnant with the second child, which made her less energetic. The client was taken to a daycare center when he as a year old, and the center's teacher had reported that he would just lie down all day. Because the family moved many times, the client had experienced many environmental changes, which would of course include frequent changes of his daycare teachers.

When the client was two years old, the mother had him receive a play assessment because he seemed energy-less and depressed. When the results showed that the client was wounded and seemed not trust adults, the mother quit work and devoted her time to taking care of the client. When the client was three years old, he was sent back to the daycare center but ended up not attending after six months because he had a hard time adapting to the new environment and would cry all day. When he was five and a half years old, the mother sent him back to the daycarehe was still attending that very daycare at the time of therapy-where he adjusted well. But the problem was that when he was feeling displeased or dissatisfied, he would curl up and would not let the problem go. It was hard to soothe him as he would retain his emotions for a long time. And he often showed a strong determination to be rebellious. For example, when the mother forbid him from eating chocolate before meal, 
Journal of Symbols \& Sandplay Therapy, Vol.6 No.2.

he would respond defiantly, saying, "I don't like chocolates. I'm never going to eat them again."

\section{Family history}

The client's mother was 36 at the time of therapy and had a bachelor's degree. She used to work as a private tutor when the client was young. The mother had difficulty in differentiating her emotions, and thus had the tendency to express all her negative emotions as "anger." The mother confessed that childrearing does not seem to be her thing, and that it seems like "work" to her. In fact, she explained that she enjoys spending her days in a state of torpor, lying down on the bed all day long without even eating.

The mother had both parents and a younger sister. She described her father as being "immature but cute, and tenderhearted." She also added that he is impulsive, not very good with money, and has no plans for the future, which makes her concerned about his health and his later years. The word she used to define her mother was "irresponsible." There had been no contact between them for the past two years. She explained that although it seemed that her mother loved her children, she constantly lied and did a lot of harm, both mentally and financially. The mother's younger sister at the time of therapy lived with her. The mother described her as "independent and smart." But although she is friendly, she had a tendency to treat her family members disrespectfully and argues that she is always right and the others are wrong.

The client's father was 41 at the time of therapy and, according to the mother, seemed depressed. He was sensitive about how the client was timid and not "manly" enough, over which he often became angry. The father's family of origin is comprised of his biological father, biological mother, stepmother, a younger brother and a younger sister. The father's parents, or the client's biological grandparents, had gotten a divorce when the father was young. It had only been a few years since the father got in touch with his biological mother. When the client's father was about 10 years old, his father remarried. $\mathrm{H}$ is younger sister was born from his father and stepmother. The stepmother vented her anger and stress she had received from her marital discord to the client's father. The father at the time of therapy was 
stuck between the quarrels of his biological mother and stepmother. He basically played the role of a mediator for everyone in the family.

The client's paternal grandfather was irresponsible, as a husband and a father. He also engaged in a regular conflict with his new wife. The stepmother, or the client's paternal step-grandmother, holds a grudge about the fact that she had to work because her husband was financially incompetent. She often told the client's father, "Why do I have to feed you when you're not even my own child?" She was also susceptible to frequent mood swings, often cursed at her husband and screamed to the client's father, "Get out of here with your father!" When the client's father got married, she demanded that he give her a monthly allowance of 500 thousand Korean won (around 500 US dollars), but he refused because it was too much and instead gave her 200 thousand KRW. As a resistance to the father, the paternal step-grandmother began working again and complains nonstop about her situation. As for the client's biological paternal grandmother, the mother feels that she is selfish, though she is sorry for the fact that she is not economically well off.

The client's brother was 15 months younger that he is. He took advantage of the fact that the client was less physically strong than he was, and often teased or hit him. Even the client's mother admitted that her younger son was naughty and sneaky. Whenever the two engaged in a fight, the little one always won.

\section{Summary of the case}

It seemed that the client had felt the mother's negative emotions even during prenatal stage. The mother had considered the client as an unwanted child since pregnancy, and did not have enough energy to spare to take care of him after birth as she suffered from a state of depression and anger. She only fulfilled the basic duties as a mother, having no emotional interactions with him. In fact, it seemed that she had sometimes poured out her anger on the client when he had been just a baby. The client, who was quite docile by nature, grew up in a state of neglect, which increasingly drained him of his energy. $\mathrm{H}$ is mother's rejection cause his inner anger to build up, but he was not able to externalize it. So he would retain his negative emotions, which would be acted out through different behaviors: the client would do 
nothing, or insist on doing things his way which caused others to become highly irritated with him. To some up, the mother's rejection of the client deprived him of the experience of recognizing and regulating his emotions, which can only be learned by mother-child interaction. Thus the build-up of negative emotions led him to exhibit passiveaggressive behaviors and to have difficulty in emotional regulation.

\section{Notable characteristics in the client's sandplay therapy process}

The client did not use water; he only used dry sand to create his sandpictures. Overall, the client did not use a range of figures. He would often use specific figures repeatedly in many pictures. For example, Halloween-related figures, the firetruck and the ambulance were often used in the first half of the process. And in the latter half, the client mostly used figures related to the theme of construction.

In terms of sand usage, his play became increasingly dynamic as therapy progressed. In the beginning it was evident that he was concerned about the therapist's reaction when sand spilled outside the tray. But more than halfway in the process, he no longer cared whether sand spilled out or not. In fact, when he spilled a large chunk of sand, he played with it outside the tray. $\mathrm{H}$ is play became more and more proactive.

The client's interaction with the therapist also underwent a change. The client at the beginning had rejected the therapist, but after some time he initiated the first physical contact between the two. He also enjoyed playing floor games with the therapist.

\section{Sandplay therapy process}

Dora Kalff proposed three stages of ego development, as shown by symbolic representations in the sandtray (1980/2003, as cited in Turner, 2009). The first stage is the animal-vegetative stage. Because it is in this stage when the conscious germinates and enters the primitive world for the first time, it appears symbolically as animal and vegetation. In this 
stage, there are unclear boundaries and the materials are in their initial forms. The conscious appears in representations such as a forest, jungle, animal, vegetation, earth and so on. There is quietness, and almost an emotional silence.

The second stage of ego development is the fighting stage. The conscious will appear as being engaged in a conflict, in a confrontational manner. It creates polarities, for example, feminine and masculine or light and darkness. These polarities are equal in power, and will often appear as two struggling forces in a conflict. They can also take the form of a dark image or a light image.

Kalf's third stage of development is the adaptation to the collective. As the last stage of ego development, new attributes that become conscious become established in our everyday outer reality. It is in this stage when the ego develops a sense of achievement. The normal, everyday life scenes seem to indicate that new conscious contents have become or are becoming assimilated into awareness. In sandplay, it can be represented through scenes of an average village or community. The fight is over.

\section{Animal-vegetative stage}

\section{1) Session 1}

The client seemed frozen from anxiety. Figure shelves covered two walls of the therapy room, but the client's gaze was fixed on a particular figure. He stared without talking, without answering any of the therapist's questions.

Even after entering the therapy room the client did not touch any figures but instead repeatedly said, "I see there are so-and-sos." When the session was over, I told him that we will see again next week but the client fingered the sand rather than making a response. The therapist sat patiently, giving time for the client to leave the room. Then suddenly, the client stared at his feet and tears began to stream down his face. The therapist commented, "You seem to feel frustrated because you want to stay longer but can't." The client did not answer. Eventually the therapist had to pick up the client to adjourn to a different room but ended up hurting her wrist. The therapist felt a countertransference; she wanted to give him a hug. 


\section{2) Session 2}

The client mostly used figures related to Halloween. That he perceived the sandplay therapy as a scary place seemed to indicate the possibility that he often had scary fantasies. The area with the ball of fire seemed to be related to the client's difficulty in regulating his emotions, or anger. Fire has different symbolisms. According to Greek mythology, it was the Titan Prometheus who gave the human race the gift of fire. In Christianity, fire is a symbol of rebirth through destruction. In alchemy, fire is related to sulfur. Fire contains the opposites of purification and destruction. It is a force of life energy and change, and also of strong emotions, such as fiery love or anger.

People with the nature of fire tend to be intense, impatient and choleric ( $H$ ong, 2012). The ambulance and firetrucks also support the assumption that the fire figures are related to the client's emotional aspect, or his anger. These vehicles suggest that the situation needs to be addressed urgently. The presence of a piano also suggests that the issue is emotion-related.

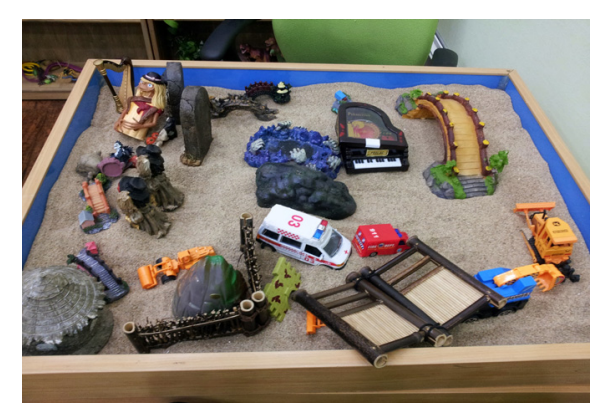

Figure 1. Sandpicture \#2

\section{3) Session 3}

The "Mother Plane" and the "Client Plane" are not yet differentiated, which can also be seen through the yellow snake. The client tried vigorously to try to make his "Maternal Grandmother" stand upright, which suggests that this grandmother figure is related to the mother and also to his issues. Because the snake sheds its skin periodically, many myths have considered this as a mystical transformation capability and identified the snake with the feminine (Choi, 2007). Yoshino Hiroko also spoke of the snake in relation to motherhood, as 
molting is similar to birthing a child (1999, as cited in Choi, 2007).

The client placed a turd in front of a snake. Snake is the symbol of motherhood. The turd may symbolize difficulties experienced during the anal stage, in relation to the mother. It was during the client's anal stage when his younger brother was born. Perhaps taking care of the client during this period was probably extremely difficult for the mother, causing further neglect.

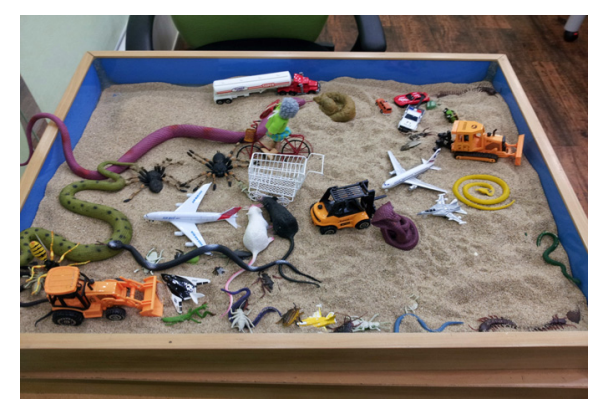

Figure 2. Sandpicture \#3

2. Fighting stage

\section{1) Session 4}

It seemed that the two-headed dinosaur, the two witches, the igloo and the black cave signify the need for union. The two-headed dinosaur also seemed to symbolize the client's ambivalent feelings.

Cinderella is a symbol of negative mother complex. In the fairytale, Cinderella is able to overcome the abuse by her stepmother and stepsisters. Her story portrays the psychological process of being able to walk the path of unconscious and succesfully achieve self-realization amid internal struggles (Lim, Yeu, Ryu, 2014).

\section{2) Session 5}

All figures in the tray were knocked over, suggesting that everything was broken due to an accident. In the middle of the tray was a big bridge, which was also knocked over. The bridge can be considered a conduit for relationship, being able to unify and connect 
psychological factors (Turner, 2009). But in this session, we can see that the bridge is not properly serving its function.

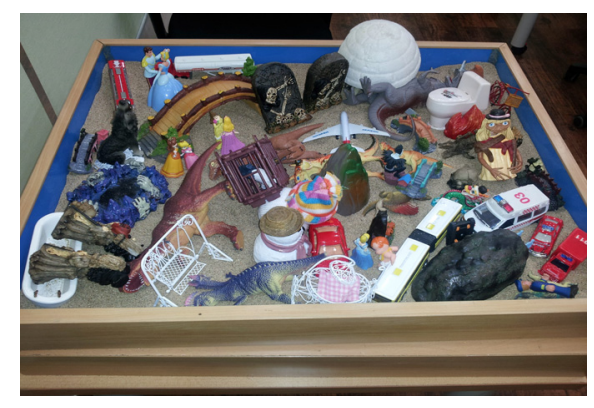

Figure 3. Sandpicture \#4

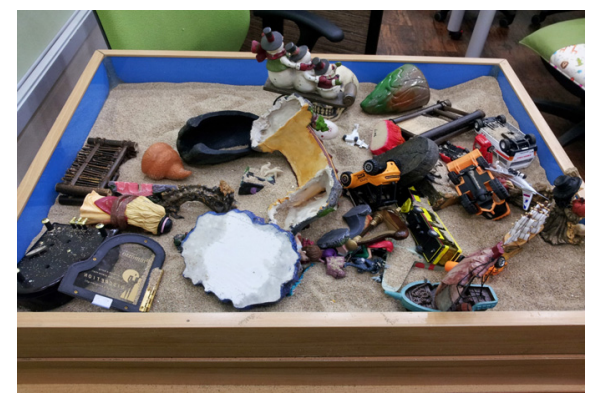

Figure 4. Sandpicture \#5

\section{3) Session 8}

The client explained that the "Ghost" is dead, which is scaring him, and placed a partition in front of the skull to block him. Because a cave is right next to it, the skull seemed to be related to motherhood. The cars are moving at a very fast speed. There was a fire, which explains why there are a fire truck, an ambulance and a police car. The client said that there is a big fire, but the fire is only a toy. The fire was eventually extinguished. The comment that the fire is only a toy and that the race cars are moving very fast mean that the client's ego has been strengthened. Saying that the fire was put down is related to his gaining the ability to control fire.

\section{4) Session 9}

There is a conflict between the airplane that fly in air and vehicles on the ground. This seemed to represent the conflict between the two realms, and also the inner conflict of the client. The client fed sand to the skull, which seemed to be intended to revive the skull.

\section{5) Session 12}

The tractor hid the skull. The skull should not be seen. A horrible thief lives in the village. The cars have come to defeat the skull as it is a scary being. The helicopter fell into 
the sand and was rescued by the cars. But then a car broke down so a tow truck came over to fix it. Trapped in a jail behind the skull, the car is screaming for someone to save him. The cars are doing their best to defeat the skull. The client's comment about defeating the skull seems to refer to his anger. In order for the cars to run normally, it is indispensable that he does works related to the skull, which symbolizes his emotional aspect.

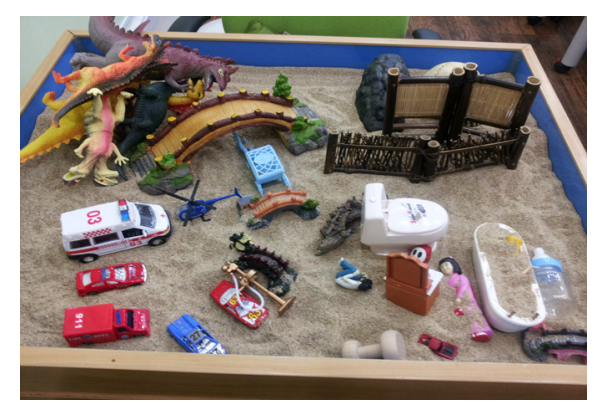

Figure 5. Sandpicture \#8

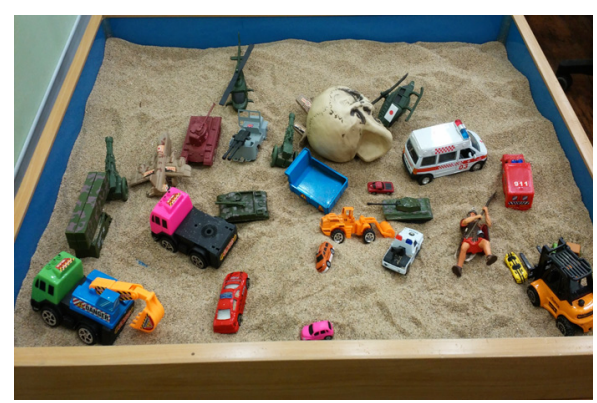

Figure 6. Sandpicture \#9

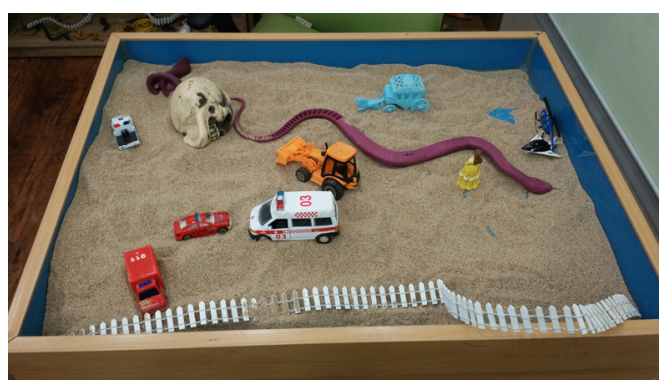

Figure 7. Sandpicture \#12

\section{6) Session 16}

There are treasures of the sea. It seems that the negative mother archetype is in the process of transforming into a positive one. The client mentioned that the elephant has three eyes, which is the major characteristic of the Hindu god Ganesha. Ganesha is a deity of holy wisdom, invincibility and discernment. The third eye represents the union of the opposites, which could mean the union of negative and positive mother archetypes. The appearance of a basket, the function of which is containment, is also positive as it is a symbol of the maternal breast (Choi, 2007). 


\section{7) Session 17}

A police truck is there to help. The police represents certain restrictions or regulations within the conscious. In that respect, it seemed that the appearance of a police truck suggested that the client had developed a being that enables regulation and mediates inner conflicts. The wolf seems to howl toward the direction of the skull, leading us to think that perhaps it represents mourning of something dead in the client's inner world.

\section{8) Session 19}

The client during the session explained that he and his father liked different robots. He had begun to separate himself from his father and accept their differences. That he became conscious of the fact that the dinosaur has two heads seemed to indicate the client's becoming conscious about his ambivalent emotions, or something in his inner world that needs to form a union. He also projected his positive aspects to the red car, and his weakness to his little brother.

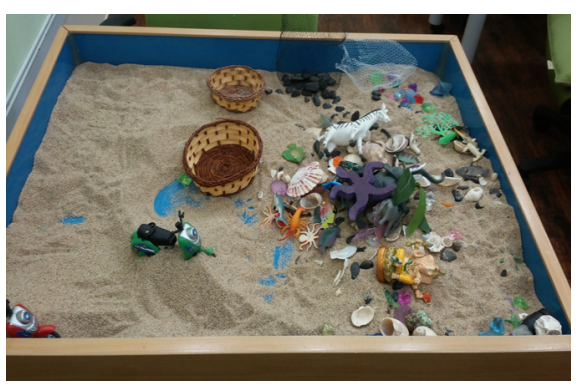

Figure 8. Sandpicture \#16

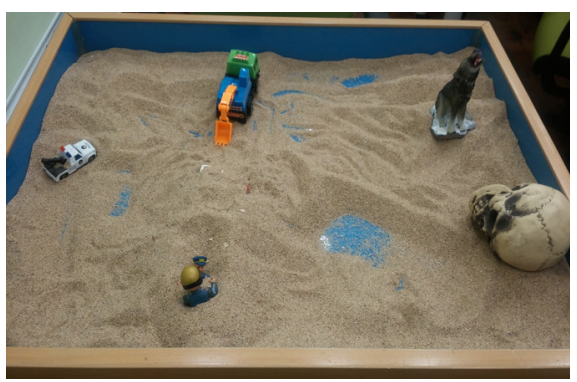

Figure 9. Sandpicture \#17

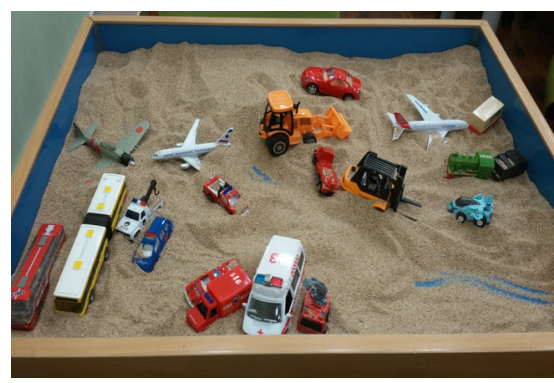

Figure 10. Sandpicture \#19 


\section{Adaptation to the collective}

\section{1) Session 20}

The house is related to a client's physical state. It is also a space in which the conscious dwells. The appearance of a new house could mean a transformation in one's attitude or conscious (Taylor, 2009). We can interpret this house as the beginning of the establishment of the client's psychological realm, which is attributable to his ego development. There are many airplanes nearby the house, which leads to the assumption that perhaps they are related to joy as well as the establishment of his psychological realm.

\section{2) Session 21}

It seemed that a massive construction project was being conducted. It was as if basic works were being done to construct something. The client created the picture quite seriously, in silence. The therapist made sure that he was not disturbed, and felt a sense of divineness from the picture. It seemed that the client was, to some extent, feeling comfortable with the changes and was now ready to move onto the next stage of development.

\section{3) Session 22}

The client touched the sand dynamically, which is related to the growth of his enthusiasm. The presence of a gas station suggests that construction will progress smoothly. The way that the client created the sand mound reminded the therapist of a process of gathering and mustering the inner energy. It seemed as if the client was amassing his Self energy.

The tree is related to the mother, or spiritual and/or mental development. It is considered a symbol of death and rebirth (Choi, 2007). It is also related to the life energy. It can also be considered as a direct example that the client is entering into a new stage of development. The circular shape of the sand mound is a symbol of wholeness, or unity (Tressider, 2007). The mound and the streetlamp are connected. The circular shape of the mound is associated with the Self, whereas the squareshaped streetlamp can be a symbol of the ego. The pole of the streetlamp can be considered as an ego-Self axis. It symbolizes the 
ego-Self connection and also shows differentiation. This is in relation to Edinger's third stage of ego and Self development, where the ego is still in a state of co-existence with the Self to some extent but at the same time partially coming to consciousness. The streetlamp is said to symbolize divineness, signs from gods, creation of the universe and universal principles (Cooper, 1987), and also a symbol of ego consciousness.

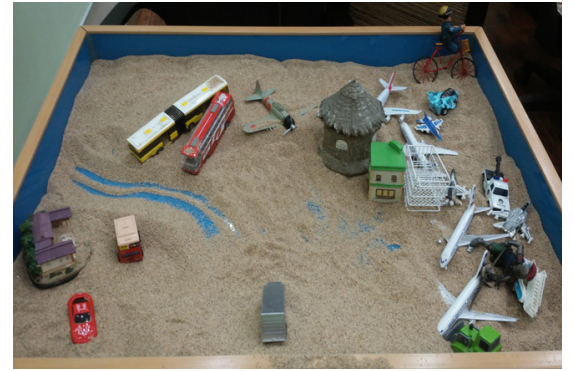

Figure 11. Sandpicture \#20

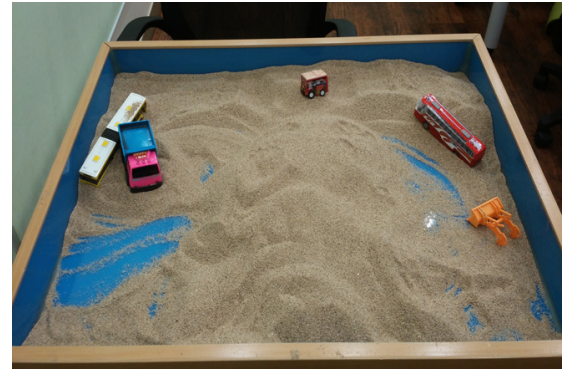

Figure 12. Sandpicture \#21

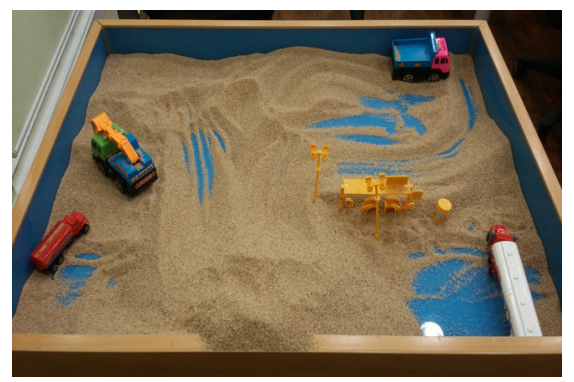

Figure 13. Sandpicture \#22

\section{4) Session 23}

There is a "treasure island." The word "treasure" can mean materialistic goods such as gold and jewels. The process of finding the treasure brings hardships and the "ultimate test." And through the treasure we are able to meet our true nature (Cooper, 1987). In the treasure island there are seashells, jewels, pebbles and so on. The seashell is something auspicious, erotic and related to the moon, as well as a symbol of the feminine (Choi, 2007).

In this sandpicture, the pebbles symbolize eternal life (Tressider, 2007). But with the arrangement of these positive symbols, the client also seemed to have become aware of, or 
conscious of, the skull again. The therapist tried to contain the client's anxiety. It seemed that the skull and the treasure island needed to be connected and in order for them to do so, positive nurturing on the part of the mother was indispensable. At this point in time, it seemed that positive nurturing was developing in the client's mother.

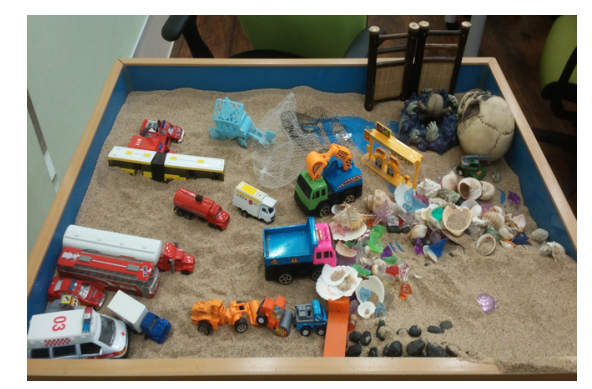

Figure 14. Sandpicture \#23

\section{5) Session 24}

The atmosphere of the story was gradually becoming increasingly positive. To the inhabitant, the house is the center of the world, a place of peace, a venue for meditation, and where one becomes united with the mother's breasts (Luc, 2006). The fact that new cars were being sold from the house seemed to indicate that the ego was becoming anew.

The client fiddle with the turd figure, being pleased of its existence. This indicates that his inner works are progressing smoothly (Taylor, 2009).

The client shared food with the therapist, developing a relationship and building a rapport.

A white tiger is housed inside a cage. The tiger has the symbolism of both creation and destruction (Cooper, 1987). The tiger in this sandpicture seemed dangerous; his frightful nature seemed unregulated. N ext to the tiger are two elephants. The elephant is a symbol of ancient sovereign authority. It is a positive symbol, representing the virtue, dignity, wisdom and prudence of a good king as well as peace, fertility and so on (Tressider, 2007). Its symbolism is opposite from that of the tiger. It seemed that while development and the establishment of a positive psychological realm were occurring, there still persisted fear in relation to the uncontrolled. 


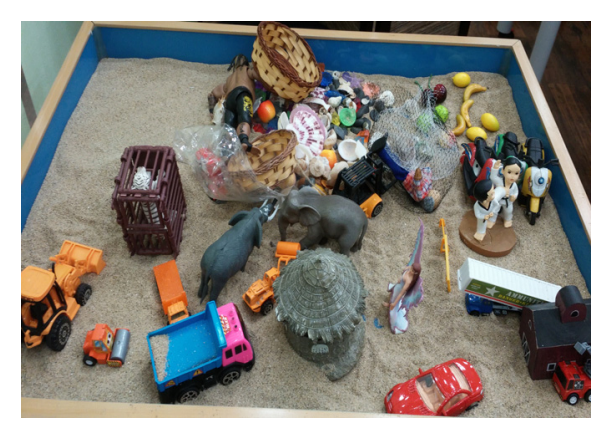

Figure 15. Sandpicture \#24

\section{6) Session 30}

The client emphasized the igloo and the food as something positive, forming images that are related to positive mother archetype. The client stressed that the igloo and food are something positive.

The domeshaped igloo has the function of containment, a characteristic of the mother archetype (Turner, 2009). The client said that he had received eight presents for his birthday. The number eight has the meaning of realization, balance, relaxation, perfect harmony, mediating realm between the circle of the sky and the square of the ground (Luc, 2006). The circle and the square are known to be a symbol of the Self and the ego, respectively, and the number known to mediate the two is eight. We can think of it in the context of the mound and street lamp that appeared in the previous picture.

A noticeable move made by the client was that he sprinkled the sand in the ray, which is an act that can be seen in myths related fertilization of land. The act of sprinkling sand in sandplay therapy refers to the attitude that the client is aware of the sacredness of life. It is an act which shows that the client recognizes deep inside that he is inevitably connected to all existing beings. It is a gentle, sacred act that seems almost like a religious ritual (Turner, 2009).

\section{7) Session 32}

The client drew concentric circles at the beginning; these circles are a symbol of the universe in a broad sense (Fontana, 1994). The client played with the police figure, which 
represents the masculine, in a fun and energetic manner. The police is a symbol of certain restrictions or regulations within the conscious (Taylor, 2009).

In reality, the client had joined a soccer club and became less intimidated in the presence of his peers. What was shown in the sandpicture and what was happening in the client's outer reality were coherent.

When conversing about the therapy's termination, he seemed sorry but was not greatly upset or anxious. The mother reported with satisfaction that she no longer has to make strenuous efforts not to become angry at the client.

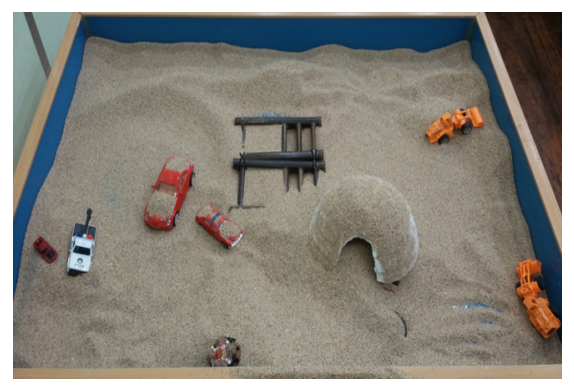

Figure 16. Sandpicture \#30

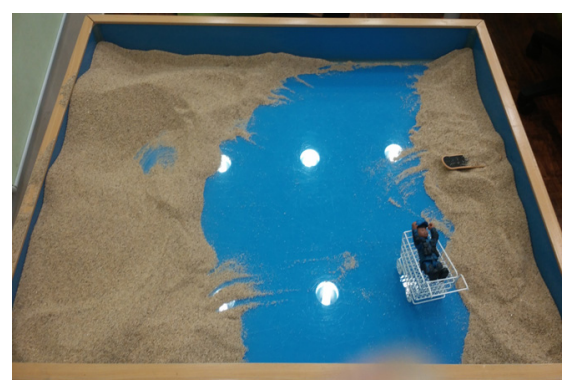

Figure 17. Sandpicture \#32

\section{8) Session 34 - Termination}

Preparations were made six weeks prior to the termination, with the client coming to therapy once every two weeks. The mother reported that the client did cry a bit when having a conversation about terminating the therapy. But the mother suggested some alternatives for him and they were able to make a compromise without emotional withdrawals. Nevertheless, it was regrettable that his emotions were not expressed in the therapy room. There were more physical contacts on the part of the client than in other sessions. The client also complained of a headache and a stomach ache, which seemed to be related to his having to say farewell. It seemed that the police officer on a skateboard will be able to enjoy his life while being able to regulate it appropriately. We can see that there are many people who are cheering him on. With regard to the married couple, marriage represents union of the opposites in alchemy (Choi, 2007). Moreover, the fact that the client extended the area of the sandtray space 
through a bridge figure gave the therapist the hope that what the client gained through sandplay therapy will be "extended" to his everyday life.

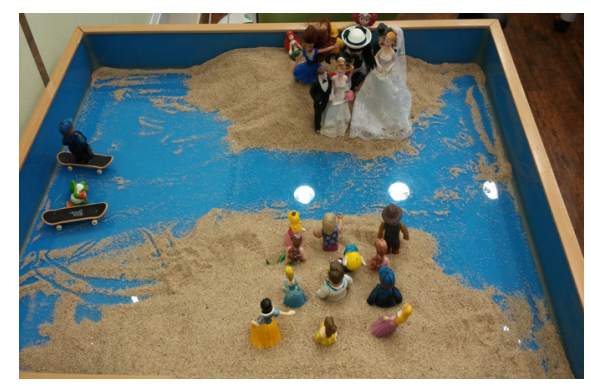

Figure 18. Sandpicture \#34-1

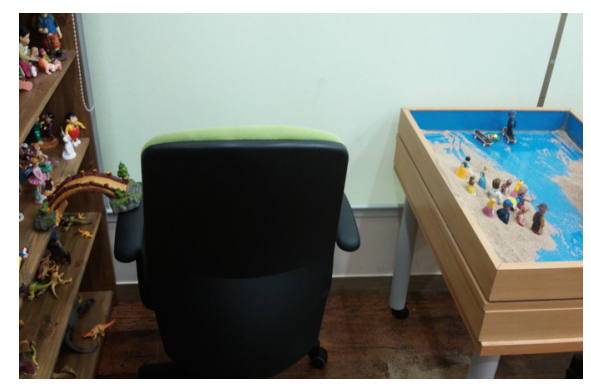

Figure 19. Sandpicture \#34-2

\section{Conclusion and Discussion}

According to Mitchell (2009), the sandtray is an aggregation of images comprised of themes related to wounding and healing. As therapy progresses, the tray shifts from the theme of wounding to the theme of healing. The 28 sandpictures dealt with the mother's hidden anger and depressions. And through the expressions of his fear and sadness, the client was able to reinforce his Self and ego and bring healing to his regulation problem.

The first ego development stage of Dora Kalff (1980/2003, as cited in Turner, 2009) is the animal/vegetative stage. The client's first three pictures fall under this stage. By representing horrifying fantasies through the scene of a Halloween party as well as by using snakes, spiders, rats, dinosaurs, insect figures and so on, he was able to recognize the issues surrounding him and his mother.

The second stage is the fighting stage, to which pictures from sessions 4 through 20 belong. The client used fighting scenes of people or dinosaurs, skull, fire and so on as negative symbols and tried to regulate or do away with them. Also, opposite figures such as the igloo and the cave, and waterfall and the skull were engaged on confrontations. In the 16th session, Ganesha appeared and attempted to unify them. 
The third stage is adaptation to the collective, which we saw from the 21st session to the end of the therapy. A largescale construction scene appears in the 21st session. The client was so serious and focused in creating the picture that the therapist was careful not to make any sound even while breathing. In the 22nd session, the self-ego axis is formed, and they are separated. In the 25th session, a community appears for the first time. And the appearance of a boat signified the beginning of a journey to everyday life. At this point in time in real life, the client's relationship with the father improved noticeably, which presumably aided the development of his masculine. Thus in the picture made in session 32 we see an active, playful boy (the police) riding on a skateboard. In session 34, we see people cheering for the client, who also appeared in the picture made in session 32, and the client shows off his skateboarding skills in front of the crowd.

By adapting to the sandtray environment, the client was able to see his issues through images. With the strengthened Self and ego, he was able to regulate his emotions. He was able to verbalize his state of being angry, and even when getting upset he would soon feel better and return to his normal emotional state. He was able to establish good peer relationships in kindergarten; his relationship with his mother improved and he was increasingly becoming considerate of her. And he was able to developing his masculine as a healthy boy.

Shore (2014) explained that emotional regulation is not just about controlling negative emotions, but also about positive emotion and the ability to withstand the new that brings unfamiliar emotional experiences. The client in this case was able to experience that ability through sandplay therapy. It is expected that the client will faithfully accomplish his future development tasks.

\section{References}

Kim, K. E. (2011). Maternal depression, parental efficacy, and involvement in play and children's social and emotional competence. The Korean Journal of Human D evelopment, 18(4), $1-17$. 
Kim, S. 0. (2010). A sandplay case study of a ten-years-girl who witnessing the mother's suicide. Korean Journal of Sand Play Therapy, 6(2), 25-65.

Lee, B. Y. (2006). A nalytical psychology. Seoul: Ilchokak.

Lee, C. J. (2002). Through the analysis of the unconscious symbolic stone and water studies. Ewha W omans University Graduate Thesis.

Lim, B. Y., Yeu, H. R., \& Ryu, M. H. (2014). Archetypal imagination in traditional fairy tales and the aesthetics of early childhood education. Journal of Eco Early Childhood Education, 13(4), 205-231.

Choi, Y. S. (2007). Tales, symbolism, unconscious. Gyeongbuk Gyeongsan: Yeungnam University Press.

Choi, W. 0. (2007). Mythic discussion about maternal cultures: the origin and archetype of maternity. The Journal of Korean Classical Woman Literature, 14, 185-222.

Hong, E. (2012). Reading Modern English Poetry with the Theme of Fire. Journal of Teaching English Literature, 16(2), 211-231.

Boik, B. L., \& Goodwin, E. A. (2000). Sandplay therapy: a step-by-step manual for psychotherapists of diverse orientations. New York: W. W. N orton \& Company.

Cicchetti, D., \& Cohen, D. J. (2006). Developmental psychopathology(2nd ed.). New Jersey: Wiley.

Cooper, J. C. (1987). An Illustrated encydopaedia of traditional symbols. New York: Thames \& Hudson.

Fontana, D. (1994). The secret language of symbols: a visual key to symbols and their meanings. San Francisco: Chronicle Books.

Luc, B. (1991). Signes, symboles et mythes. Paris: Presses Unversitaires de France.

Mitchell, R. R. (2009). Sand play themes, expressed in the healing process. Korean Association of Sandplay Therapy Conference Materials, 3-6.

Schore, A. N. (2014). Attachment, neuroscience sandplay I. Korean sodety of Sandplay Therapy Conference $M$ aterials.

Taylor, J. (1998). The Living Labyrinth. N ew Jersey: Paulist Press.

Tressider, J. (2000). Symbols and Their M eanings. London: Duncan Baird.

Turner, B. A. (2005). The handbook of sandplay therapy. California: Temenos Press. 
Eun Kyung Jang / Sandplay Therapy Case Study: A Boy with Difficulty in Emotional Regulation

Weinberg, B. (2014). Attachment, neuroscience sandplay П. Korean sodiety of Sandplay Therapy Conference $M$ aterials.

Received: [30] [10] 2015

Revised: [01] [12] 2015

Accepted: [25] [12] 2015 